\title{
The Development of Oroqen People's Cultural Industry Under the Wave of Consumerism
}

\author{
Liyuan Xu \\ Department of Sociology, School of Law and Sociology, Yunnan Normal University, Kunming, China
}

Email address:

liyuaninynnu@sina.cn

To cite this article:

Liyuan Xu. The Development of Oroqen People's Cultural Industry Under the Wave of Consumerism. International Journal of Economic Behavior and Organization. Vol. 9, No. 2, 2021, pp. 36-41. doi: 10.11648/j.ijebo.20210902.12

Received: June 8, 2021; Accepted: June 30, 2021; Published: July 13, 2021

\begin{abstract}
Due to the particularity of Oroqen people and the severe compression of living time and space, in the face of the wave of modernization, the deconstruction of modernity to traditional culture and the reflexivity of modernity itself, Oroqen people have a dilemma in the development of national cultural industry. In the current consumer society, how to make good use of opportunities to develop their own and national traditions has also become an important issue in the study of the development of Oroqen people. By combing the digestion of modernity on historical habits and comparing the local cases of successful transformation, the author finds that the transformation of ethnic cultural industry in Oroqen should coordinate its liquidity characteristics, so as to better grasp the convergence of cultural context in the process of foreign cultural adaptation. This paper uses the research logic of literature analysis and ordinary methodology to explore the ideas that can be used for reference in the development process of ethnic cultural industry of Oroqen people. Combined with the characteristics of the media in the Internet era, this paper explores the future development path of Oroqen people. At the same time, it can also provide a model and experience for the inheritance and protection of ethnic culture in other provinces, cities, counties and even other regions abroad, and realize the exchange and mutual learning of civilization.
\end{abstract}

Keywords: The Deconstruction of Modernity, Cultural Consciousness, Industrial Development

\section{Introduction}

The complex knowledge system of cultural holders is usually expressed by means of specific verbal narration and behavior. If the alien cultural subjects want to truly recognize the other, they should not only fully understand the special narrative logic of the other culture, but also fully understand the unique symbolic metaphor of the other behavior. But when the cultural holder initiates and expresses his own culture speech, he must obtain a kind of free cultural mood, loyalty to the meta-culture, rather than enter in a cultural destructive posture.

At present, the academic research on the development of ethnic cultural industry in Oroqen mostly focuses on the description of economic and non-material cultural protection, and rarely discusses the development of ethnic cultural industry in Oroqen from the perspective of ontology and remote experience comparison. In the face of the serious phenomenon of blind development in the process of modernization in ethnic minority areas, "all look to money" tendency, this paper innovatively starts from the structural tension of modernity, calling for the return of spiritual culture to maintain national survival and development. At the same time, in methodology, it is noted that the cultural construction of national subject lacks self-consciousness, and most scholars usually take the blindness of theme "entry". In order to guard against the unification of "no civilization anywhere" in the development of national culture in ethnic minority areas, the Oroqen people should remember to look back on the unyielding "forest spirit" in the process of taking root in the mountain. In the development of national culture, it is not too urgent to let the trap of consumerism swallow up the precious national tradition.

\section{The Deconstruction of Modernity}

Edward Burnett Tylor discussed in Primitive Culture that the primitive society was a natural worship of Pan spiritual 
things. Nearly a hundred years later, Baudrillard's Consumer society came out and proposed that people in modern society were trapped in the worship of symbolic value. Commodity worship was formed around "objects" in capitalist mass production. Modern people in the wave of consumerism were surrounded by objects and plagued by constantly updated science and technology. Similarly, in the process of national culture development, the capital inertia of profit-seeking makes consumerism continue to expand, as Weber predicted in Protestant ethics and capitalist spirit that with the development of capitalism and the accumulation of wealth, people' s arrogance, anger, physical desire, eye desire and desire for life also grow in proportion. [1]

Our life world is represented by various symbols. These symbols enable consumers to find the additional meaning behind their purchases, not their use value, and this meaning is "fashion". When consumers pursue this symbol of "fashion", "fashion becomes the "eternal motivation" to maintain consumerism in the consumer society. For example, topics such as "Hermès Kelly Bag" and "Shot Shoes" that are very popular on the Internet appear with the meaning of consumption segmentation, which shows this endless, and the symbol of a mountain is higher than a mountain. Symbol or fashion consumption has brought a hysterical world. Just as sociologist Georg Simmel said, "Money is only a bridge to the ultimate value, and people cannot live on the bridge". Only by finding a balance with the world can Oroqen people find the position of individuals and ethnic groups in the world.

\subsection{The Cage of Rationalization}

Rationalization is one of the main logic lines running through Marx Weber's historical development of human society.

The dilemma of rationalization is also a problem that has to be faced in the development of cultural industries in ethnic minority areas. Marx Weber sadly asserts that human beings are stepping into the "rational cage" set by themselves for the creative motivation caused by cultural rationality to cater to the market. When the development and inheritance of culture is driven by the simple economic production goal, as the prevalence of fast food culture, the production of standard and uniform mass culture is driven by the laws and forces of non-personality, which leads to the killing of cultural freedom, personality and creation. [2]

With the strengthening of people's rationalization in modern society, it is often difficult to escape from "McDonald" sization. Rationalization extinguishes the characteristics of independent individuals. The development of ethnic areas in Oroqen will inevitably learn from and imitate the experience of other successful cases, but between the coordination of overall interests and the maintenance of their own survival, it is necessary to firmly grasp the excellent quality and cultural essence of Oroqen people, and consolidate the foothold of sustainable development in the future in the existing conditions.

\subsection{The Establishment of Green Development Concept}

Under the wave of modernization, it is particularly important to establish the concept of green development, which is of scientific and forward-looking significance not only for individuals who are helpless in the face of outside culture, but also for the whole Oroqen ethnic group culture who are unprepared when facing the impact of globalization.

Since the reform and opening up, the rapid development of more than forty years, when we open the door, we should pay attention to overcome the inertia of capital logic and consumerism trap, because the logic and inertia of capital makes the development of productive forces have the potential to destroy the material ecological environment on a large scale. Only on the premise of a correct understanding of the ethnic ecology of the Oroqen people, adhere to the concept of green development as the main core of sustainable development measures, can create a reliable source of material basis for the future development of the Oroqen people.

\section{Cultural Landscape Heritage}

According to the sixth national census in 2010, the total population of Oroqen is 8659 . Compared with the statistical data in 2000, it only increases by more than 500 people, which is a slow growth. According to the data of the National Bureau of statistics, by 2010, the number of natural villages in China had decreased from 3.6 million ten years ago to 2.7 million, with a total decrease of 900000 villages in the past ten years, and an average of nearly 300 villages disappeared every day. [3] The people in the original village of Oroqen live a life of "flesh and skin". With the development of modernization, they often come down to the choice of "culture" or "human", which seems to be a commonplace topic in Anthropology and sociology. But in essence, culture is created by people, and people can transform the culture they create with the change of environment, In order to form a cultural atmosphere to adapt to the new environment.

The biggest bright spot in the development of ethnic minority areas is the cultural characteristics of the nation. In the southwest of the motherland, Yunnan, as a major province of ethnic minorities in China, there are also many direct ethnic groups in the process of modernization. However, in the development of cultural tourism, it can be said that it is more successful, which has certain reference significance for the development of ethnic culture and commerce in Oroqen.

In February 2021, Wengding, the original village disappeared in the sea of fire, is to make full use of the uniqueness and historical nature of its national architecture to retain fully and completely for commercial activities, while the aboriginal people move to the dam of convenient transportation to live, enter the Wengding village for folk performance within the prescribed time, and live in the dam at other times. The consumption of tourists in the village is finally distributed to the aboriginal hands in the form of wages. Similarly, in Lijiang, northwest Yunnan, Yuhu Village 
under Jade Dragon Snow Mountain was basically a village isolated from the world. With the deepening of the development of snow mountain, Villagers took the east wind of tourism to transform on the basis of the original traditional production. The Nakhi had the habit and hobbies of raising horses and flowers in the courtyard. They retained the previous adobe house, were willing to transform in the village road, and used horses for tourists to travel on the mountain. The tradition and modernity have been well combined. Like Jinning, where the king's seal of Yunnan was excavated around Kunming, the NORTHSTAR GROUP, a developer, seized the local culture, relying on the background story of the king's seal of Yunnan, developed a series of commercial developments such as ancient Yunnan museums and classical docks on the basis of protecting cultural traditions, and also took advantage of the geographical advantages of local hot springs to start building ancient Yunnan series of hot spring farms, hotels and amusement parks and other projects to attract residents around holidays for short-distance leisure consumption. Most importantly, all the ancient Yunnan theme buildings developed by the NORTHSTAR GROUP are very realistic to restore the original architectural appearance of the ancient Yunnan people, bringing a very strong sense of experience.

The Oroqen settlement can also refer to similar development paths to explore a sustainable breakthrough combined with modern commercial development, and use modern concepts to play a greater development potential in the space with national cultural connotations.

\subsection{Space Time Compression}

John H. Bodley, an American anthropologist, once defined the indigenous people who are in the dilemma of production and life in the face of the impact of modern society as victims of development. [4] Under the leadership of the Communist Party of China, the Oroqen people achieved the leap from the primitive commune system to the socialist society in less than 70 years. In the process of national economic development and policy planning, because of the particularity of the Oroqen people, when dealing with the changes of ecological environment, culture and social form, the Oroqen people are unable to deal with their own development prospects and resource allocation within the ethnic group, as James G. Flanagan said, "The response of small, equal societies, which once represented the final apartheid of mankind, to external contact will lead to the emergence of new divisions within their societies."[5]

\subsubsection{The Lost Field}

When the Oroqen people bid farewell to the forest where their ancestors lived and walked from the mountain to the foot of the mountain, with the changes of living environment and production and working methods, the cultural imprint of their own nation was "rubbed" indistinctly in their daily life, and the inheritance of spiritual and material culture became precarious.

Through the form of local legislation to set up a model, and gradually sort out the intangible cultural heritage, and archive, and through the joint local education departments and relevant social organizations, publicize and compile the existing memory of Oroqen culture. In addition, we should also set up a certain reward mechanism to commend individuals or groups who have made outstanding contributions to the protection and inheritance of intangible cultural heritage, guide the society to attach importance to the work, stimulate the master's mentality, and better participate in the process of cultural protection.

\subsubsection{The Rhythm of Reorganization}

The different characteristics and life rhythm of nomadic and farming peoples are reflected in the process of modernization integration. The stable social rhythm of generations is suddenly blocked when it meets the tide of modernization. The original field habits are constantly shaped and continued in the return. For the long-term interests of race, the Oroqen people have to adjust and adapt to the new social rhythm.

In the process of national cultural development, capital has impacted the values of the people of Oroqen once and again. They "abandon hunting and returning to agriculture" and lay down the natural resources for generations to survive, and lose traditional industries. Local governments should find the direction suitable for the development of life plan of Oroqen when opening up corresponding green channels, In the short time of self-sufficiency, we can better adapt to the development of globalization in the future and provide more powerful material guarantee for inheriting the national spiritual culture.

According to Article 12 of Chapter I of the education law of the people's Republic of China, it is mentioned that "schools and other educational institutions mainly for ethnic autonomous regions and students of ethnic minorities shall, in light of the actual situation, use the national language and the language and language commonly used by their own or local nationalities to carry out bilingual education"[6]. It also mentioned that the state has taken measures to provide conditions and support for bilingual education in schools dominated by minority students and other educational institutions. [7] The local government should also combine the intangible cultural heritage content and historical tradition, compile school-based teaching materials and develop local ethnic customs practice activities, so as to give full play to the positive role of schools as an educational position.

In addition, relying on the intellectual resources of regional colleges and universities, courses on Oroqen language and cultural protection and inheritance should be set up to further strengthen and publicize the national culture with regional characteristics. At the same time, the local education department can integrate the cultural resources at hand, recruit students, researchers and volunteers from related majors such as cultural industry, sociology, anthropology, linguistics and so on from all over the country and even the world, and carry out cultural investigation in 
Oroqen settlement, so as to participate in promoting the development and construction of local culture.

In the process of developing and cultivating Oroqen people's livelihood, we should pay attention to their national habits and psychological characteristics, guide and dredge them in time, and mobilize the mentality of the masses as masters, so as to "take the lead of the government and work hard on their own", instead of falling into the blind working state of giving priority to blood transfusion in carrying out ethnic work in the past, After going down the mountain, Rejuvenate actively adapts to all kinds of maladjustment brought by the change of production and labor, and promotes the sustainable development power of the nation.

\subsection{Structural Equilibrium}

The structural functionalism founded by Parsons has always been a corner in the academic circle, which emphasizes social stability and balance. It holds that the social system is an organic whole, which is composed of internal functioning and interacting subsystems. The change of one subsystem may lead to the change of other subsystems In the late 1950s, due to a series of adjustments in social and economic structure and government policies, the Oroqen people broke away from the tradition of primitive hunting in the mountains for generations, gradually walked out of the forest and began to "settle down" in the northeast of Heilongjiang Province and the Xing'an Mountains of Inner Mongolia Autonomous region.

The land assets related to peasants in Oroqen include cultivated land, homestead, collective construction land and woodland, most of which cannot get rid of the transformation and operation of urban capital. Experts say that the difficulty of revitalizing rural idle assets lies not in funds or technology, but in how to ensure that the main body of income generated by revitalizing assets is peasants. [8] Therefore, the idle assets of peasants in Oroqen can be cleaned up, and then cooperatives can be set up. Through the form of cooperatives, these idle assets can be operated by outsourcing companies, so as to ensure the status of peasants as the main beneficiaries, and establish a mechanism in which Oroqen is the main beneficiary, and dividends can be paid every year. Cooperatives employ professional talents to do special management, through different forms to revitalize the idle asset set, develop local skills, increase the collective income and increase the income of peasants at the same time, so as to achieve the goal of increasing household income.

With the sweeping wave of modernization and the influx of foreign population and culture, the original settlement of Oroqen people has been replaced by modern villages and towns. When the mode of production and life is transforming, the national culture is also changing quietly. As a result, the existing social structure has both plasticity and vulnerability in the dual change of economic base and superstructure, In the end, how to make the Oroqen people better adapt to modern life and where to go has become a problem that later scholars have been exploring.

\subsubsection{The Construction of Symbols}

As an important measure to improve competitiveness in regional research, city branding has been playing a more and more important role in promoting regional economic development and shaping local image in recent years. For example, the most common brands such as red Fuji apple, Dandong strawberry and Yunnan tobacco, which are packaged with crops as carriers, are endowed with deep geographical brand, When consumers consume, they will remember the source of symbols, and then when the source launches new products again, because of the original impression label, they are more inclined to choose the source of symbols memorized in their mind.

Among the regional economic development strategies, Kumamon Prefecture of Japan launched the "Kumamon" strategy. The local government used the network marketing means to build momentum, to win over the traffic bigwigs and new media public opinion, successfully created the image of "Kumamon", and led to the landing of field travel, trademark endorsement and other additional industries, At the same time, through the publicity of these industries, the brand appeal of "bear" has been strengthened, and the consumer market that promotes economic development has been stabilized.

On the other hand, the descendants of the Oroqen people regard themselves as bears and worship them as totems. Compared with the "bear" created by filling in the virtual network, the original resources of the Oroqen people should be more excavatable and creative. Just as the first reaction to see Tao Huabi's head is "Lao Gan Ma", and the first reaction to hear "Erdos" is Inner Mongolia's wool products, the promotion of Oroqen culture also needs to select representative and distinctive signs to form a unique brand label, and then affect the effect of related industries.

In the process of national modernization, the Oroqen people mostly play the role of self-sufficiency and stay in the production link. They need to further open up the channels of exchange, expand the consumer market and feedback the Oroqen traditional culture through the improvement of the cultural industry chain.

With the gradual implementation of the policy of banning hunting, many local handicrafts have been restricted to a certain extent in the acquisition of production raw materials, but it does not affect the Oroqen people to realize the continuation of their ancestors' ancient skills on the basis of the original production and labor through the development of breeding industry. In the process of exchange and cooperation, considering that most of the finished products are presented in the form of fur, the target consumer group can be defined as the middle and high-end consumer body. The government of Oroqen people's settlement should strive to cooperate with well-known designers and manufacturers at home and abroad to create their own brand. In this way, we can maintain the existing living standard without losing the selling price.

\subsubsection{Cultural Consciousness}

Influenced by structural functionalism, American 
sociologist Immanuel Maurice Wallerstein, on the basis of inheriting Marx's political economy and class analysis, draws lessons from the external cause analysis method of "center periphery" model of dependency theory and Jean Baudrillard's proposition of "economic world" of civilization and economy, sums up an internal cause explanation of modernization theory. However, when applied to the analysis of Oroqen's cultural change, it is easy to fall into the standard framework based on economy to measure which culture is better or worse.

It is from the practice of daily life that hunter gatherers understand the whole world they live in. [9] The culture of Oroqen people has developed to now, and it is mostly spread in oral history with its myths and customs. Although the mottled traces of characters have been found, the vocabulary has been kept in daily life. Some linguists and sociologists believe that the differences between languages not only reflect the needs and environmental impact of the language speakers, but also influence the way the language speakers see the world. [10] This view has evolved into the later Sapir-Worf Hypothesis, which holds that language reflects values. Similarly, Oroqen people's national character and action logic are hidden in their context dialogue. For example, Australians like to simplify their vocabulary and add "ie" or "Y" at the end of the word (such as using prezzie to represent present and matey to represent mate). This can be seen as a way to express their humor, friendliness and easiness. [11] In the retrospection of Oroqen's language and culture, some local scholars and officials are also following up cooperation and exchange, such as cooperating with Olga Morozova, director of Foreign Language Department of Amur State University in Russia, to explore Oroqen's language and culture, and holding a global Tungusic culture seminar in Heihe city.

In his early years, Xiaotong Fei, one of the founders of sociology and anthropology in China, made an investigation on the living conditions and livelihood transformation of the Oroqen people. At the end of last century, he keenly found that a realistic dilemma that had to be faced with in the modernization of China's ethnic minorities, that is, "does the modernization of ethnic minorities mean a greater degree of Sinicization?" [12] Based on the development of the Oroqen people and the thinking about the future of ethnic minorities under the current globalization, Xiaotong Fei proposed "cultural consciousness". Cultural consciousness means that people living in a given culture have "self-knowledge" of their culture, and understand its origin, formation process, characteristics and development trend. The purpose of "self-knowledge" is to strengthen the independent ability of cultural transformation and obtain the independent position of deciding the cultural choice to adapt to the new environment and new era. [13]

In response to the cultural development of various ethnic groups, Xiaotong Fei left a 16 character proverb on his 80 th birthday, which is widely circulated in the academic circles: "each is beautiful, the beauty of beauty, beauty and common, the world is great". [14] A s for the gradual development and protection of the cultural industry of the Oroqen people, we should not create diversified colors in order to present diversity. We should use modern means to carry forward and inherit the Oroqen national culture on the basis of original capital.

\subsection{Superimposed Social Network}

In the space-time of Internet as carrier, digital presentation and flow heat, information exchange and transaction consumption are characterized by fast, novel and scientific and technological. In the new historical starting point, the Oroqen people should find a way out for their own nation's survival and development in a new way and idea.

With the development of Internet technology and logistics transportation, people's consumption purpose has gradually changed from the initial emphasis on the value and practicality of use to the stage of development and enjoyment The consumption trend gradually presents the characteristics of intelligence and diversification, and consumers themselves tend to choose products with strong sense of experience.

Since the outbreak of COVID-19 in 2020, the consumption of data on the Internet platform has been showing more momentum than ever before. It also indicates that the "cloud consumption" of "staying indoors and knowing the world" has become a new trend for future industrial development. The large and small Xing'an Mountains are rich in animal and plant resources and excellent ecological environment. The people of Oroqen, who live in the world, have formed traditional customs with unique national customs. Local governments can cooperate with relevant advanced technology companies at home and abroad, learn from the practice of successful cases such as "Cloud Tour Forbidden City" and "ant forest", and launch practical routines such as VR cloud tour, virtual adoption of animals Virtual adoption of trees and other online software integrating the culture and ecological environment of Oroqen people can attract tourists' experience, promote the interaction between tourists and local industries, and finally generate benefits through the way of cash in Internet traffic.

In addition, we can invite self media bloggers, Internet TV and tourism experienced teachers with certain popularity to participate in the traditional festivals of the Oroqen people, actively listen to the opinions of the tourism industry, and innovate the publicity methods and expand the influence on the basis of maintaining the traditional essence.

\section{Conclusion}

At present, the development of tourism culture in minority areas is always entrapped by the profit-seeking view of consumerism, and the blind following of short-sightedness is easy to lose its own characteristics and even forget its cultural advantages. The excessive commercial development encountered by China's "four ancient cities" in the development process has become a lesson in the development of national culture. In today's consumer society, as a direct nation of Oroqen people in the wave of modernization, how 
their future development, in the face of gradually blurred national memory and historical heritage where to go, has been the research topic of scholars to explore.

This reminds me of Herman Bausinger's Folk Culture in the Technological World. It tells us how the influence of technology changes the old life relationship, how the original narrow social sight city is broken, how new social structure, new cultural forms and new ways of thinking are produced. [15] In the process of ethnic culture development of the Oroqen people, grasping the opportunities brought by consumerism can realize the linkage development of snowball, and help to find the missing links in the industrial chain, and provide theoretical practice for the formation of the industrial model of ethnic development of the Oroqen people. But because of human greed, we must guard against the trap of consumerism. In the process of promoting the modernization transformation of the Oroqen people, we should respect and fully explore the cultural context of the nation.

Industrialization has directly or indirectly changed all social fields and endowed new features for the folk culture of cities and villages. [16] It is a single-edged challenge for the Oroqen people, but we should believe that the culture of "pure people" is not always untouched by the mode and network of the technological world. These simple people know how to deal with the changes and requirements of the technological world with full grasp. The most important thing is how they do not forget their original heart, adhere to the peace of mind, and shape the spirit of Oroqen in the new era with wisdom and perseverance. It is the power guarantee for us to protect and inherit national culture in the process of developing Oroqen national culture.

\section{References}

[1] Max Weber, Protestant Ethics and capitalist spirit [M]. Translated by Yan Kewen. Shanghai: Shanghai People's publishing house, 2018: 321.

[2] Randall Collins, Michael markovsky. A journey to discover Society: a review of Western Sociological Thoughts [M]. Beijing: Zhonghua Book Company, 2006: 394-398.
[3] Qianqian Lian. Research on the end types and dynamic mechanism of villages in Central Agricultural Areas -- Taking Gongyi City as an example [D]. Henan University, 2014.

[4] John H. Bodley. Victims of development [M]. Trans. He Xiaorong, Xie Shengli, Li Wangwang. Beijing: Peking University Press, 2011.

[5] James G, Flanagan. Hierarchy in simple "egalitarian societies" [J]. Annual Review of Anthropology, 1989 (18).

[6] Rangcao Cai. Practical research on Tibetan Chinese bilingual teaching of electromagnetics [D]. Qinghai Normal University, 2019.

[7] Shangyun Li. Research on ethnic policy of the People's Republic of China [D]. Central University for nationalities, 2004.

[8] Xiaoyun Li. To revitalize idle assets in rural areas, we should ensure that peasants become the main beneficiaries -- Based on the experiment of urban driven Rural Revitalization in six villages in Kunming suburbs [J]. Rural work communication, 2020 (13): 19-21.

[9] Tim Ingold. The Perception of the Environment: Essays on Livelihood, Dwelling and Skill, London and New York: Routledge, 2000, pp. 1-7.

[10] David bopuno. Sociology [M]. Trans. Li Qiang et al. Beijing: China Renmin University Press, 2007: 57.

[11] Wierzbicka, Ann. 1986. "Dose language reflect culture? Evidence from Australian English." Language in society 15: 349 374.

[12] Xiaotong Fei. The pattern of pluralistic integration of the Chinese nation $[\mathrm{M}]$. Beijing: Central University for Nationalities Press, 2003: 37.

[13] Xiaotong Fei. Reconstruction of Chinese culture [M]. Shanghai: East China Normal University Press, 2013: 156, 35.

[14] Jue Cui. Historical investigation and contemporary context of cultural confidence $[\mathrm{J}]$. Journal of Guangdong Institute of socialism, 2017 (04): 14-18.

[15] Zhen Zhang. Faith conversion embedded in the network [D]. Liaoning University, 2018.

[16] Cuixia Zhang. Modern technology, daily life and folklore research thinking [J]. Folk study, 2018 (05): 14-22 + 157. 